EDITORIAL

\title{
Avanzando en el fortalecimiento y mejora contínua de la Revista Médica Hondureña en tiempos de pandemia
}

\author{
Advancing in the strengthening and continuous improvement of the Revista Médica Hondureña in pandemic times
}

Con la publicación de este Número 1 del 2021, la Revista Médica Hondureña ha avanzado en el proceso de fortalecimiento y mejora continua planteado en 2019. ${ }^{1}$ Los artículos incorporan cambios de formato y contenido que la acercan a los parámetros de calidad requeridos en la publicación científica vigente. Estos aspectos incluyen las exigencias legales para compartir contenidos licencia Creative Commons, la identificación de artículos DOI (Digital Object Identifier) y la identificación de autores ORCID (Open Researcher and Contributor ID), los cuales se han actualizado en las Instrucciones para Autor.

Actualmente la Revista opera bajo la licencia Creative Commons Atribución 4.0 Internacional (CC BY 4.0, https://creativecommons.org/licenses/by/4.0/deed.es), ${ }^{2}$ mediante la cual el usuario es libre de compartir, copiar y redistribuir el material en cualquier medio o formato, y adaptar, incluyendo remezclar, transformar y construir a partir del material para cualquier propósito, incluso comercialmente. Los términos de atribución requieren dar crédito de manera adecuada, brindar un enlace a la licencia, e indicar si se han realizado cambios. Puede hacerlo en cualquier forma razonable, pero no de tal manera que sugiera que la persona o el uso que la persona está procurando, tienen el apoyo del licenciante. No hay restricciones adicionales por lo que no puede aplicar términos legales ni medidas tecnológicas que restrinjan legalmente a otros a hacer cualquier uso permitido por la licencia. La Revista obtuvo la licencia CC BY 4.0 en el mes de febrero de 2021.

En este período la Revista se registró en AmeliCA (http:// portal.amelica.org/microPortal.oa?opcion=acerca) y en CAMJOL (Central American Journals Online, https://www.camjol. info/index.php/index). AmeliCA es una infraestructura de comunicación para la publicación académica y la ciencia abierta, sostenida de forma cooperativa y centrada en el modelo de publicación sin fines de lucro para conservar la naturaleza académica y abierta de la comunicación científica. CAMJOL es una base de datos de revistas publicadas en Nicaragua, Honduras y El Salvador, que abarca toda la gama de disciplinas académicas y cuyo objetivo es dar mayor visibilidad a las revistas participantes y la investigación que éstas trasmiten. El registro en CAMJOL ha permitido contar con el identificador DOI para los artículos. El DOI es un enlace persistente a un objeto de investigación (artículo, revista, conjunto de datos, capítulo de libro, libro completo, entre otros). ${ }^{3}$ Tiene las características de ser único, persistente y proporcionar acceso al objeto de información, el cual puede ser acceso abierto o acceso de suscripción. Debido a estas carac- terísticas, usar un DOI para referirse a un artículo proporciona un enlace más estable que simplemente usar un localizador de recursos uniforme (URL, del inglés Uniform Resource Locator). Este es el primer número de la Revista en el cual se incorpora $\mathrm{DOI}$ a los artículos y en el que los autores se identifican con el registro ORCID. EI ORCID proporciona un identificador digital, único, gratuito y persistente que distingue un investigador de otro, y puede conectar su ID con su información profesional: afiliaciones, subvenciones, publicaciones, revisión por pares y más. Las instituciones también se benefician al garantizar que el trabajo producido por sus investigadores se les atribuya, favoreciendo mayor presencia y visibilidad. ${ }^{4}$

Todos estos aspectos relacionados a normalización y trazabilidad de la publicación científica, posicionan mejor a la Revista para ofrecer un espacio óptimo de divulgación científica a sus usuarios, lectores, autores y editores. Asimismo, le permitirá optar a otras bases de datos internacionales y aumentar su visibilidad regional y global. El Consejo Editorial continuará avanzando en este plan de fortalecimiento con el apoyo de la comunidad científica que participa activamente de la Revista. Enhorabuena por estos logros en tiempos tan difíciles como lo son los tiempos de la pandemia de COVID-19.

Jackeline Alger, MD, PhD (1)

Directora

Revista Médica Hondureña

Primera vez publicado en línea 26-06-2021

Dirigir correspondencia a: jackelinealger@gmail.com

Declaración de relaciones y actividades financieras y no financieras y conflictos de interés: ninguno.

DOI: https://doi.org/10.5377/rmh.v89i1.11763

(C) 2021 Autor(es): (c) (i)

\section{REFERENCIAS}

1. Alger J. Fortalecimiento y mejora continua de la Revista Médica Hondureña. Rev Méd Hondur. 2019; 87: 5.

2. Maradiaga E. Licencias Creative Commons: licencias de libre acceso y su funcionamiento. Rev Méd Hondur 2021; 89: 71-72.

3. Wilkinson LJ. El papel crítico del DOI. SciELO en Perspectiva [Internet]. 2018 [citado 11 junio 2021]. Disponible en: https://blog.scielo.org/ es/2018/08/02/el-papel-critico-del-doi/

4. ORCID: Conectando investigación e investigadores [Internet]. ORCID; 2021 [citado 11 junio 2021]. Disponible en: https://orcid.org 